Please do not remove this page

RMIT

UNIVERSITY

\title{
The effect of target thickness on the ballistic performance of ultra high molecular weight polyethylene composite
}

Nguyen, Long; Ryan, Shannon; Cimpoeru, Stephen; Mouritz, Adrian; Orifici, Adrian

https://researchrepository.rmit.edu.au/esploro/outputs/9921862325901341/filesAndLinks?institution=61RMIT_INST\&index=null

Nguyen, L., Ryan, S., Cimpoeru, S., Mouritz, A., \& Orifici, A. (2015). The effect of target thickness on the ballistic performance of ultra high molecular weight polyethylene composite. International Journal of Impact Engineering, 75, 174-183. https://doi.org/10.1016/j.ijimpeng.2014.07.008

Document Version: Accepted Manuscript

Published Version: https://doi.org/10.1016/j.ijimpeng.2014.07.008

Repository homepage: https://researchrepository.rmit.edu.au

(C) 2014 Elsevier Ltd.

Downloaded On 2023/04/26 18:26:01 +1000

Please do not remove this page 
Thank you for downloading this document from the RMIT Research Repository.

The RMIT Research Repository is an open access database showcasing the research outputs of RMIT University researchers.

RMIT Research Repository: http://researchbank.rmit.edu.au/

\section{Citation:}

Nguyen, L, Ryan, S, Cimpoeru, S, Mouritz, A and Orifici, A 2015, 'The effect of target thickness on the ballistic performance of ultra high molecular weight polyethylene composite', International Journal of Impact Engineering, vol. 75, pp. 174-183.

See this record in the RMIT Research Repository at:

https://researchbank.rmit.edu.au/view/rmit:30066

Version: Accepted Manuscript

Copyright Statement: (c) 2014 Elsevier Ltd Creative Commons AttributionNonCommercial-NoDerivs 3.0 Unported License.

Link to Published Version:

http://dx.doi.org/10.1016/j.ijimpeng.2014.07.008 


\title{
The Effect of Target Thickness on the Ballistic Performance of Ultra High Molecular Weight Polyethylene Composite
}

\author{
L.H. Nguyen ${ }^{1,2}$, S. Ryan ${ }^{3}$, S.J. Cimpoeru ${ }^{3}$, A.P. Mouritz ${ }^{1}$, A.C. Orifici ${ }^{1}$ \\ ${ }^{1}$ School of Aerospace, Mechanical and Manufacturing Engineering, RMIT University, GPO Box 2476, Melbourne, Australia \\ ${ }^{2}$ Defence Materials Technology Centre, 24 Wakefield St, Hawthorn, Victoria 3122, Australia \\ ${ }^{3}$ Defence Science and Technology Organisation, 506 Lorimer St, Fishermans Bend, Victoria 3207, Australia
}

\begin{abstract}
The ballistic performance of thick ultra-high molecular weight polyethylene (UHMW-PE) composite was experimentally determined for panel thicknesses ranging from $9 \mathrm{~mm}$ to $100 \mathrm{~mm}$ against $12.7 \mathrm{~mm}$ and $20 \mathrm{~mm}$ calibre fragment simulating projectiles (FSPs). Thin panels $(<\sim 10 \mathrm{~mm}$ thick) were observed to undergo large deflection and bulging, failing predominantly in fibre tension. With increased thickness the panels demonstrated a two-stage penetration process: shear plugging during the initial penetration followed by the formation of a transition plane and bulging of a separated rear panel. The transition plane between the two penetration stages was found to vary with impact velocity and target thickness. These variables are inter-related in ballistic limit testing as thicker targets are tested at higher velocities. An analytical model was developed to describe the two-stage perforation model, based on energy and momentum conservation. The shear plugging stage is characterised in terms of work required to produce a shear plug in the target material, while the bulging and membrane tension phase is based on momentum and classical yarn theory. The model was found to provide very good agreement with the experimental results for thick targets that displayed the twostage penetration process. For thin targets, which did not show the initial shear plugging phase, analytical models for membranes were demonstrated as suitable.
\end{abstract}

Keywords: UHMW polyethylene, terminal ballistics, penetration mechanism, analytical model

\section{Nomenclature}

\begin{tabular}{cl}
\hline Symbol & Parameter \\
\hline$A$ & Area \\
$A D$ & Areal density \\
$C$ & Empirical constant \\
$c$ & Wave speed \\
$E$ & Elastic modulus \\
$E_{x}$ & Energy \\
$k$ & Shear plugging thickness ratio \\
$M$ & Mass per unit length \\
$m$ & Mass \\
$r$ & Radius \\
$T$ & Tension force \\
$t$ & Thickness \\
$V$ & Velocity \\
$v$ & Volume fraction \\
$\beta$ & Radius multiplier \\
$\varepsilon$ & Strain \\
$\rho$ & Density \\
$\sigma$ & Normal stress \\
$\tau$ & Shear stress
\end{tabular}

\begin{tabular}{cl}
\hline Subscripts & Parameter \\
\hline$B$ & Bulging \\
$f$ & Fibre \\
$i$ & Impact \\
max & Failure \\
$p$ & Projectile \\
$S$ & Shear plugging \\
$t$ & Target \\
$T$ & Transition \\
50 & $50^{\text {th }}$ percentile \\
\hline
\end{tabular}




\section{Introduction}

Polymer-based fibre-reinforced composites such as ultra-high molecular weight polyethylene (UHMW$\mathrm{PE})$ composite have been shown to be extremely effective against small calibre ballistic threats, particularly in weight-critical applications (e.g. personal protection vests and helmets) [1] or as contact spall liners [2]. It is considered that these materials, when applied in thicker sections, may be suitable as a primary armour component for protection against higher lethality fragmentation threats. It has also been found that the protection efficiency of some composites increases with thickness [3], which is driven by different penetration mechanisms occurring for thicker sections.

Although the ballistic performance of thin UHMW-PE composite is well known [4][5], there have only been limited published experimental results for thick targets. Heisserer and Van der Werff [6] and Heisserer et al. [7] investigated the ballistic limit and penetration of panels up to $50 \mathrm{~mm}$ and $25 \mathrm{~mm}$ thick respectively, though did not focus on the penetration mechanisms. Iremonger [8] and Greenhalgh et al. [9] found that thicker laminates show penetration under two distinct stages: an initial penetration stage characterised by shear failure of the fibres, and a second stage where partial penetration by the impactor causes a sub-laminate to bulge or break away (breakout) and undergo deflection and bending. The second stage is similar to the failure mode seen for thin laminates [10] or fabrics [11], with fibre failure in tension the dominant mechanism close to the ballistic limit.

Following on from these findings, there is still limited understanding of the damage and penetration mechanisms of thick UHMW-PE composite. The transition between the initial shearing stage and the bulging stage is not well understood, and the thickness of the sub-laminate formed in the bulging stage has not been characterised. Greenhalgh et al. [9] showed that thicker laminates exhibited a range of damage mechanisms, and demonstrated the occurrence of delamination, ply splitting, and fibre-matrix debonding. However, the fibre failure morphology was not characterised in this work, which is critical as the fibres are primarily responsible for the load-carrying and energy absorbance of the material. The ballistic performance of UHMW-PE composite for targets thicker than $50 \mathrm{~mm}$ has not been reported, and a clear definition has not been made of the transition between thin laminates showing only bulging, and thick laminates with two-stage penetration.

Analytical models of ballistic performance are critical to predicting performance in armour applications, and also provide significant insight into the governing penetration mechanisms. However, there are no models in literature that have been specifically developed for thick UHMW-PE composite, and no models for other composite materials that have been validated for use with thick UHMW-PE composite. Analytical models have been developed for composites under ballistic impact [10][12][13], but these models are not suitable for thick UHMW-PE composite as they are based on a single perforation stage. Gellert et al. [3] developed a multi-stage analytical model for thick GFRP based on energy laws to describe penetration by indentation, tensile failure, delamination and bulging. However, this model does not account for shear failure and also relies on several empirical constants, and as such cannot be applied to thick UHMW-PE composite.

In this paper, an experimental investigation is conducted into the deformation and failure mechanisms of thick UHMW-PE composites impacted by fragment simulating projectiles (FSPS). Ballistic limit tests have been performed on panels up to $100 \mathrm{~mm}$ thick, the results of which are used to identify the penetration mechanisms and study the morphology of the fracture surface through the laminate thickness. An analytical model for the ballistic limit is then developed based on energy and momentum laws, which also takes into account the specific behaviour of UHMW-PE composite observed in experimental testing. Predictions of the ballistic limit are compared with results from the experimental testing to demonstrate the capacity of the analytical model to predict ballistic performance across the range of target thicknesses investigated. 


\section{Experimental Method}

High strength gel spun UHMW-PE fibre is manufactured by, amongst others, DSM and Honeywell under the trade name Dyneema ${ }^{\circledR}$ and Spectr ${ }^{\circledR}$, respectively. In this study Dyneema ${ }^{\circledR}$ HB26 is tested. The composite consists of approximately 80 percent by weight Dyneema ${ }^{\circledR}$ SK76 fibres within a polyurethane matrix. HB26 has uni-directional plies in a cross-ply layup that is manufactured by hot pressing [0/90/0/90] layers together. Micrographs of the cross-section show a circular fibre with a diameter of approximately $17 \mu \mathrm{m}$ and a single ply thickness of approximately $60 \mu \mathrm{m}$ [14].

The HB26 laminates tested in this program were consolidated by the manufacturer under a pressure and temperature of $14 \mathrm{MPa}$ and $125^{\circ} \mathrm{C}$ respectively. Panels up to a thickness of $50 \mathrm{~mm}$ were manufactured in this manner and tested as delivered from the manufacturer. For thicker sections (up to $150 \mathrm{~mm}$ thick), not all could be directly sourced and, as such, were consolidated from thinner (25 $\mathrm{mm}$ and $50 \mathrm{~mm}$ thick) panels in a secondary hot press process at $0.9 \mathrm{MPa}$ and $125^{\circ} \mathrm{C}$. Results show that panels combined in this secondary process exhibit ballistic performance within the experimental scatter of panels manufactured at the full thickness.

Ballistic limit tests were performed for a range of thicknesses with MIL-DTL-46593B spec $12.7 \mathrm{~mm}$ and $20 \mathrm{~mm}$ calibre FSPs. A 50th percentile probability of perforation was used to define the ballistic limit, $V_{50}$. Calculation of the $V_{50}$ was determined from an even distribution of partial penetration (PP) and complete penetration (CP) results, as per MIL-STD-662F. For targets $25 \mathrm{~mm}$ thick or below, initial ballistic limit tests were performed with the panel bolted between two $8 \mathrm{~mm}$ thick steel plates with four $100 \mathrm{~mm}$ diameter apertures. To ensure confinement did not influence the test results, verification tests were performed on full panels clamped to a steel frame. Results show targets constrained by aperture plates exhibit ballistic performance equivalent to a single shot on a full panel, consistent with results from other researchers [4]. For thicker targets, tests were performed on full panels due to excessive drawing of material at the target edge using the aperture configuration. All panels had inplane dimensions of $300 \mathrm{~mm} \times 300 \mathrm{~mm}$, except for the $75 \mathrm{~mm}$ and $100 \mathrm{~mm}$ thick targets that measured $400 \mathrm{~mm} \times 400 \mathrm{~mm}$. A grid pattern of $20 \mathrm{~mm} \times 20 \mathrm{~mm}$ squares was marked onto the front and back face of the targets. The grid on the front face was used to determine the degree of in-plane deformation on the front face while the back face grid was used to track the development of the back face bulge. A summary of the ballistic limit test results is given in Table 2 .

Table 1: Overview and results of ballistic limit tests.

\begin{tabular}{cccccc}
\hline Thickness $(\mathrm{mm})$ & Projectile & No. of Test & No. used for $\mathrm{V}_{50}$ & $\mathrm{~V}_{50}(\mathrm{~m} / \mathrm{s})$ & STDEV $(\mathrm{m} / \mathrm{s})$ \\
\hline 9.1 & $12.7 \mathrm{~mm}$ FSP & 11 & 4 & 506.0 & 26.4 \\
20.0 & $12.7 \mathrm{~mm}$ FSP & 11 & 6 & 825.8 & 17.2 \\
25.2 & $12.7 \mathrm{~mm}$ FSP & 9 & 4 & 1021.4 & 8.5 \\
35.1 & $12.7 \mathrm{~mm}$ FSP & 6 & 6 & 1250.3 & 36.1 \\
50.4 & $12.7 \mathrm{~mm}$ FSP & 5 & 2 & 1656.5 & 16.3 \\
\hline 10.0 & $20 \mathrm{~mm} \mathrm{FSP}$ & 6 & 4 & 393.9 & 43.0 \\
20.0 & $20 \mathrm{~mm} \mathrm{FSP}$ & 9 & 6 & 620.1 & 19.6 \\
36.2 & $20 \mathrm{~mm}$ FSP & 12 & 4 & 901.4 & 9.8 \\
75.6 & $20 \mathrm{~mm}$ FSP & 6 & 4 & 1527.6 & 104.6 \\
101.7 & $20 \mathrm{~mm}$ FSP & 6 & 4 & 2001.8 & 91.8 \\
\hline
\end{tabular}

\section{Experimental Results}

The ballistic limit test results are plotted in Figure 3 in terms of a non-dimensional areal density variable proposed by Cunniff [1], where the target areal density is non-dimensionalised by the projectile presented area divided by the projectile mass $\left(A D_{t} A_{p} / m_{p}\right)$. Figure 3 shows that the ballistic limit results for UHMW-PE composite against different calibre FSPs collapse upon a single linear curve when plotted against the Cunniff parameter, for all panel thicknesses up to $100 \mathrm{~mm}$. The figure 
also shows the superior ballistic performance of UHMW-PE composite over Kevlar ${ }^{\circledR}$ and E-glass on a weight basis.

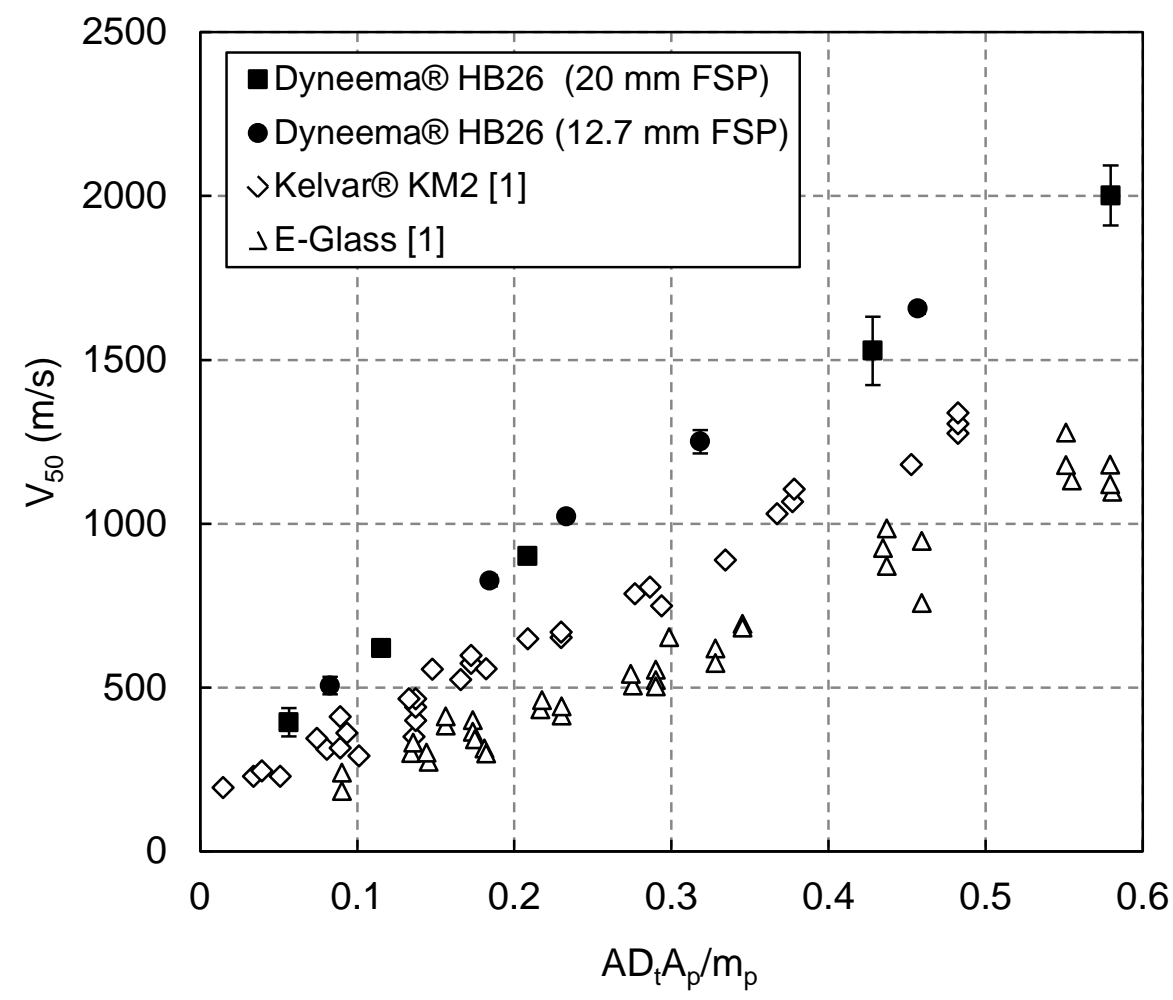

Figure 1: Ballistic limit test results plotted in terms of Cuniff's non-dimensional parameter for fibre-reinforced composites (from [1]). Existing data on $\mathrm{Kevlar}^{\circledR} \mathrm{KM} 2$ and E-Glass from [1], incorporating target areal densities between $2.7-25 \mathrm{~kg} / \mathrm{m}^{2}$ against $0.12-8.2 \mathrm{~g}$ steel or tungsten projectiles with length to diameter ratios of approximately 1.0 , is also plotted.

High-speed photography was performed during a selection of the tests to capture the transient response of the target panels, an example of which is shown in Figure 7. The panel was found to develop a bulge in the shape of a pyramid, characteristic of a cross-ply laminate [15] or cross-woven fabric [16]. Figure 7 shows the significant in-plane shear deformation that occurred during bulging, which can be seen from the highly distorted grid regions along the diagonal of the bulge. The large amount of drawing in of the material from the edges can also be seen. This is caused by the extensive deflection and the occurrence of delamination that extends to the edge of the target. 


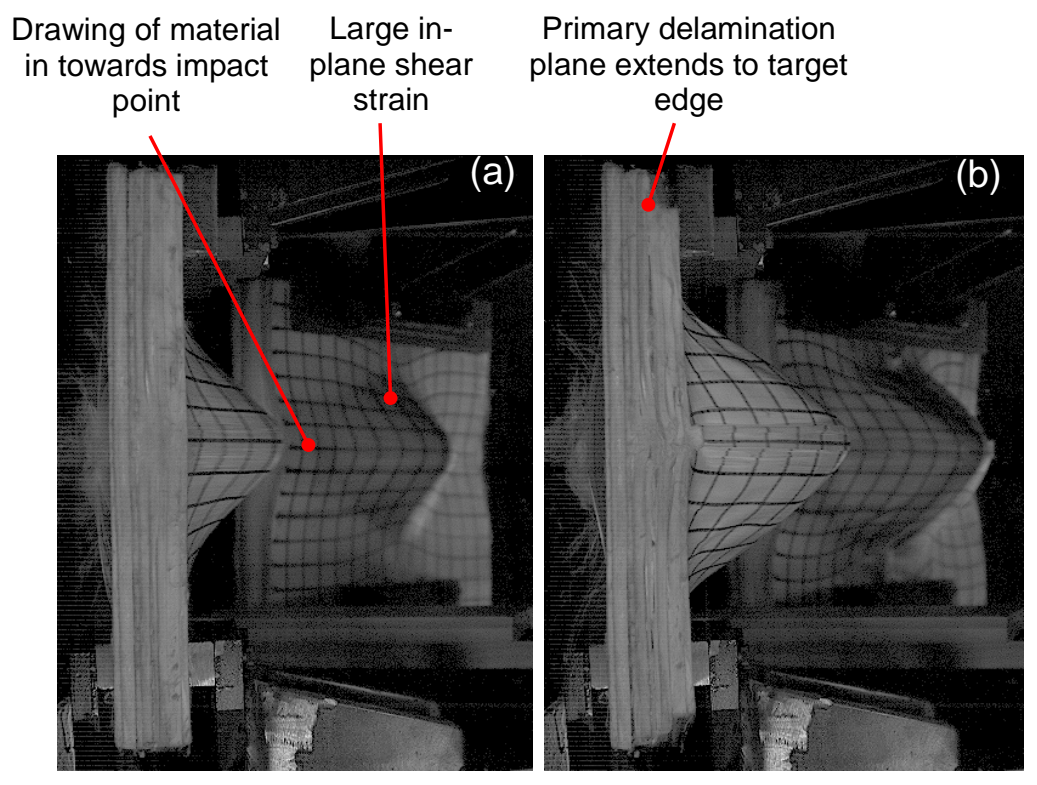

Figure 2: High-speed images of a $36 \mathrm{~mm}$ thick target impacted by a $20 \mathrm{~mm}$ FSP, (a) $200 \mu \mathrm{s}$ and (b) $450 \mu \mathrm{s}$ from initial impact.

Figure 5 shows representative damage on the front face of a target. Fibre fracture was observed at the penetration cavity and delaminations were seen throughout the laminate. Other damage mechanisms seen included fibre-matrix debonding (seen in Figure 5 as stray mostly-detached fibres) and ply splitting (seen in Figure 5 as separations in the ply that disrupt the front face grid). These damage mechanisms have been characterised in other research [9]. As shown in Figure 5, the grid on the target front face displayed little deformation away from the penetration site, indicating that the load distribution is localised around the penetration zone. At the penetration site, substantial elastic recoil of the fibres was observed in high-speed video.

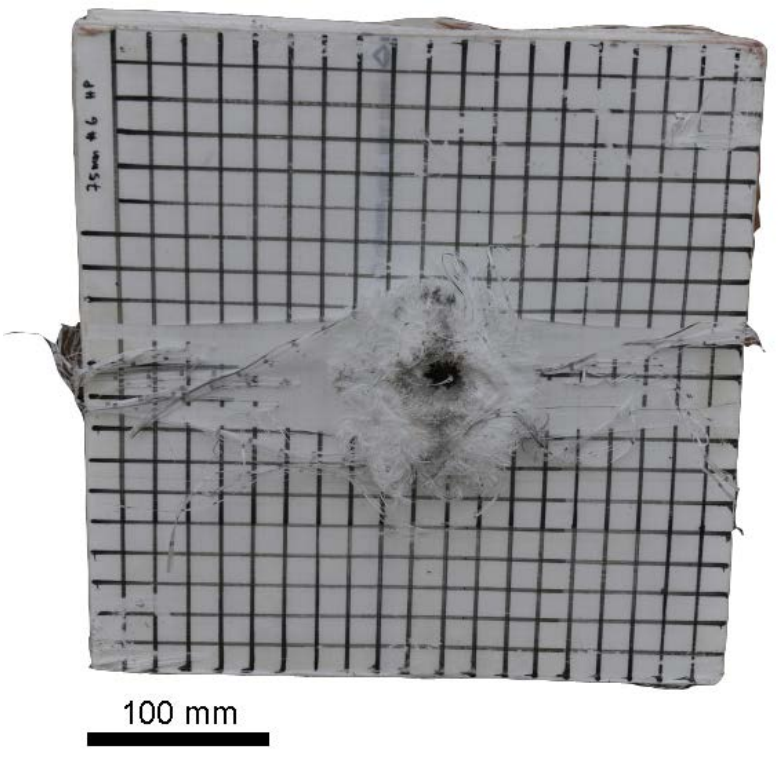

Figure 3: Ballistic limit test target front face (75 mm thick target impacted by a $20 \mathrm{~mm}$ FSP at $1594 \mathrm{~m} / \mathrm{s}$ ).

A schematic of the penetration and failure mechanisms seen in the ballistic limit tests is shown in Figure 4, representative for target thicknesses greater than $10 \mathrm{~mm}$. Due to the very low interlaminar 
stiffness and strength of UHMW-PE composite, delaminations are prevalent through the panel thickness (Figure 4a), likely formed very early in the process as a result of interaction of release waves. For thick targets, a two-stage penetration process was observed: an initial shear plugging stage, shown primarily in Figure 4(b), where there is little deflection of the target as the projectile penetrated, followed by bulging or breakout of a sub-laminate, with large deflection and drawing in of material from the panel edges, shown in Figure 4(c). The separation of these two stages is clearly defined, and likely occurs at one of the initial delamination planes. Delaminations also propagate due to the mode I opening stresses generated from the penetrator, and mode II loading due to the shear stresses developed from bending. These aspects are illustrated using SEM images of the delaminated surfaces in Figure 4, where Figure 4(e) and Figure 4(f) show fracture surfaces characteristic of mode I and mode II delamination growth. In many cases, the delaminations extended to the edge of the target, and often to all four edges. This resulted in some sub-laminates separating away and breaking the target into multiple pieces. However, in completely perforated targets it was observed that mild fibre bridging and some small intact regions within each delaminated interface meant that the target remained mostly in one piece.

For panels of $10 \mathrm{~mm}$ thickness and less, the entire panel underwent bulging (i.e. there was no transition plane).
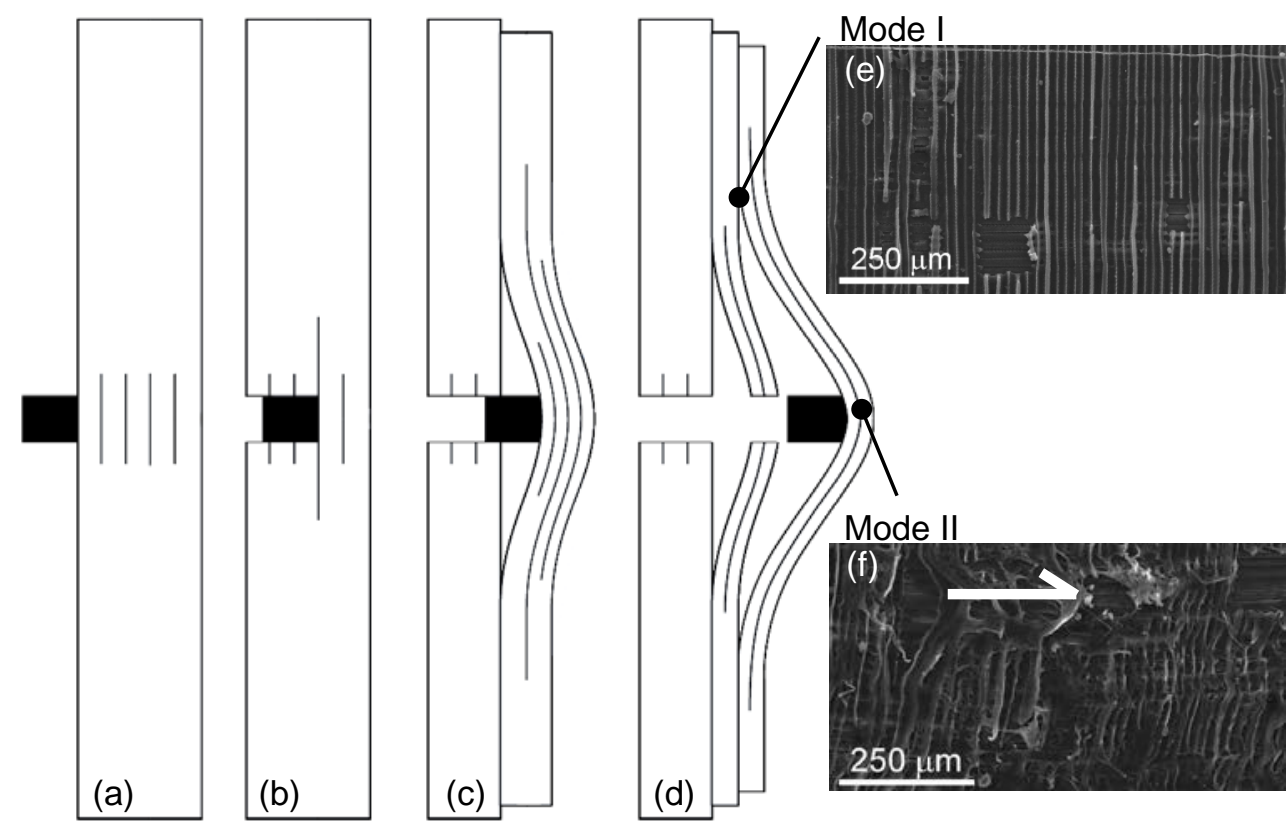

Figure 4: Penetration and damage mechanisms from ballistic tests: (a) Shock induced delamination; (b) Shear plugging and formation of the transition interface; (c) Sub-laminate bulging and material drawing at breakout; and (d) Penetration and development of sub-laminates in bulging. Micrographs of fracture surface (e) away from and (f) close to the penetration site.

Fibre fracture was characterised using SEM micrographs of fibre tips taken from the impact site through the target thickness, and is summarised in Figure 8. During the shear plugging stage (Figure 8 (a) and (b)), the fibre fracture surfaces display predominantly fibre cutting or shearing as a result of the sharp edges of the FSP. There were limited fibres displaying tensile failure in the section of the target undergoing shear plugging. However, there was significant fibre compression in the thickness direction, as seen in the flattened fibres shown in Figure 8(a) and Figure 8(b). The transverse compressive modulus of microfibrillar fibres has been shown to be approximately two orders of magnitude lower than the longitudinal modulus $[15,16]$. As such fibre tensile and compressive failures are considered of secondary importance for energy absorption, and fibre shear failure is the dominant energy absorption mechanism in the shear plugging stage. 
During the bulging stage, the prevalence of fibre transverse shear failure decreases while fibre tension failure increases. This is due to large deflection of the bulge, which creates high tensile stresses as the material stretches. Figure 8(c) and Figure 8(d) show that fibres on the back face of a ballistic limit target exhibited predominantly ductile failure, and had a very different character to the fibres failing in shear on the front face. Unlike fibres failing in shear that exhibit a clean fracture surface, fibres failing in tension undergo significant elongation and reduction in diameter. This is caused by the highly orientated molecular chains and fibrillar nature of the material, which when coupled with the weak chemical bonds allow slipping under tension [19].

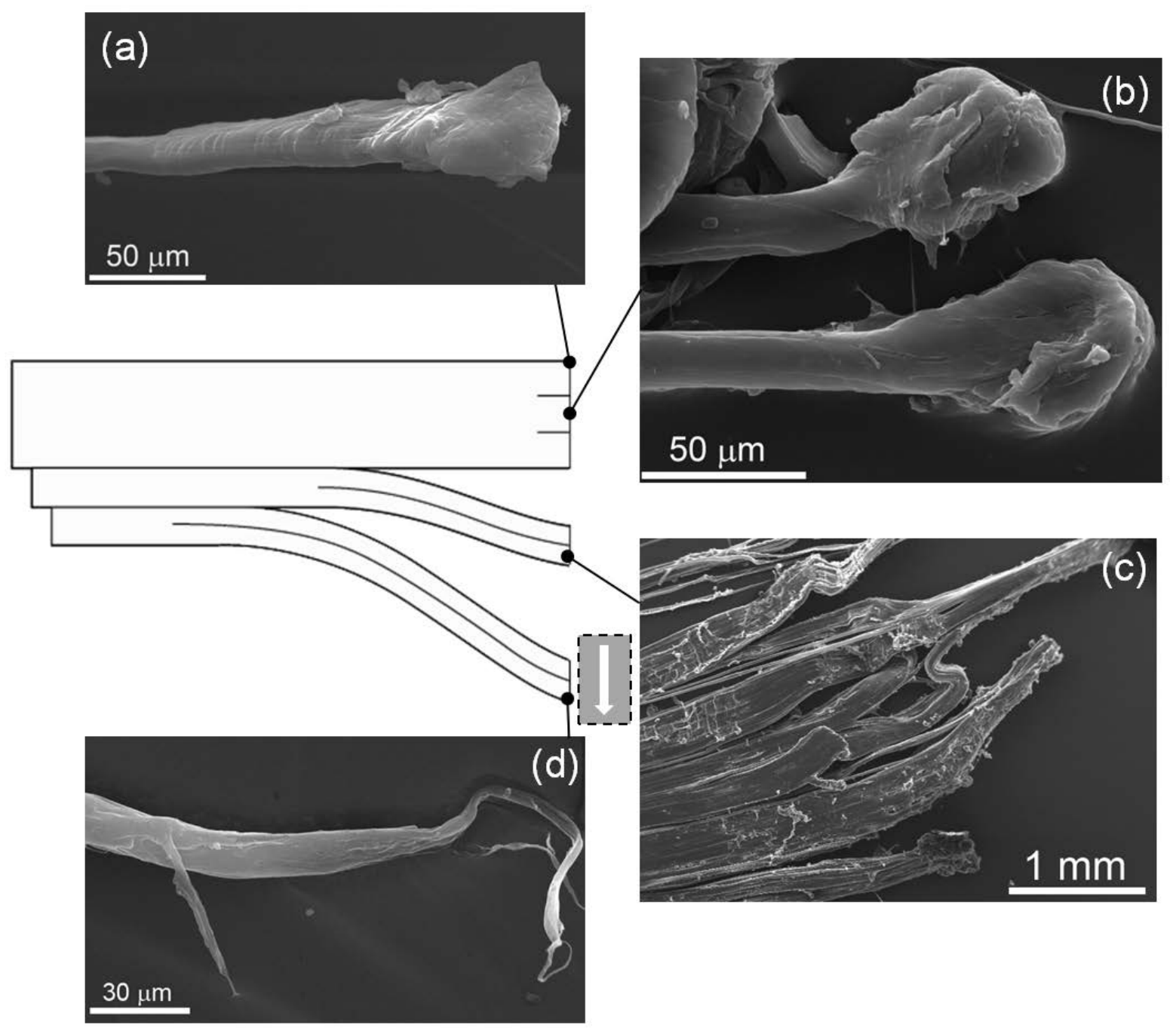

Figure 5: Fibre fracture morphology from ballistic limit tests. Images taken (a) at the front face, (b) $9 \mathrm{~mm}$ from the front face, (c) $18 \mathrm{~mm}$ from the front face, and (d) at the back face.

The observations of ductile tensile failure are seemingly in contrast to Koh et al. [20], who observed predominantly brittle cleavage fibre fracture morphologies in high strain rate $\left(850 \mathrm{~s}^{-1}\right)$ tensile test of UHMW-PE composite and only some fibres exhibiting ductile necking failure. However, they postulate that the presence of fibre ductile failure in their high strain tests is due to a temperature rise at high strain rates that induces ductile failure. This can explain why even at ballistic strain rates the fibres on the back face exhibit ductile failure instead of brittle failure, as the temperatures involved are sufficient to promote ductile failure. 
For thin laminates that displayed only bulging, tensile failure was seen throughout the laminate, with the same observations as above for the bulging stage of the thick laminates. In addition, the initial layers of the laminate were found to fail by fibre shearing.

Transition between the two penetration stages is a complex phenomenon. It has been proposed that transition is due to delamination induced by shear dominated stresses in bending [9]. However, the target undergoing shear plugging is not undergoing bending. Further, as the thickness increases, the resistance to bending increases with a cubic relationship. This suggests a dependence on thickness, with transition occurring once the sub-laminate underneath the penetrator becomes thin enough to undergo deflection. On the other hand, the occurrence of the bulging is related to the transfer of momentum to the bulging sub-laminate, and the extent to which the penetrator causes a global response involving the whole target. These aspects imply a dependence on the material wave speed and impact velocity.

Although complex to characterise, the transition from shear plugging to the bulging stage was simple to identify in the test samples. As the separation plane forms and the rear panel begins to bulge, material is significantly drawn in-plane towards the impact point. Thus, the thickness of material undergoing shear plugging, $t_{S}$, could be easily measured. The proportion of the panel that was penetrated in the bulging stage, $t_{B}$, was calculated by subtracting the shear plugging thickness from the original target thickness, $t$.

Figure 9 shows the ratio of thickness in shear plugging to total thickness as a function of impact velocity. Although plotted in terms of impact velocity in Figure 9, this could also have been plotted in terms of panel thickness due to interdependence between the two variables when tested at or about the ballistic limit (i.e. thicker panels require higher impact velocities). As the impact velocity increases (or the panel thickness increases), the proportion of the material undergoing shear plugging is shown to increase. At impact velocities below approximately $500 \mathrm{~m} / \mathrm{s}$ (or targets less than $10 \mathrm{~mm}$ thick), no transition plane was observed, as the target failed primarily in bulging. Although there was some evidence of shear failure on the surface plies, as this was only minor and there was no obvious transition plane, thin laminates were thus considered as having undergone no penetration through shear plugging. As the impact velocity increased, the thickness of material penetrated in shear plugging increased rapidly such that at impact velocities of $1000 \mathrm{~m} / \mathrm{s}$ (or targets around $25 \mathrm{~mm}$ thick) around $60 \%$ of the laminate failed in shear plugging. With further increase in impact velocity to 2000 $\mathrm{m} / \mathrm{s}$ (or $100 \mathrm{~mm}$ thickness) the shear plugging thickness approached $75 \%$ of the laminate thickness. 


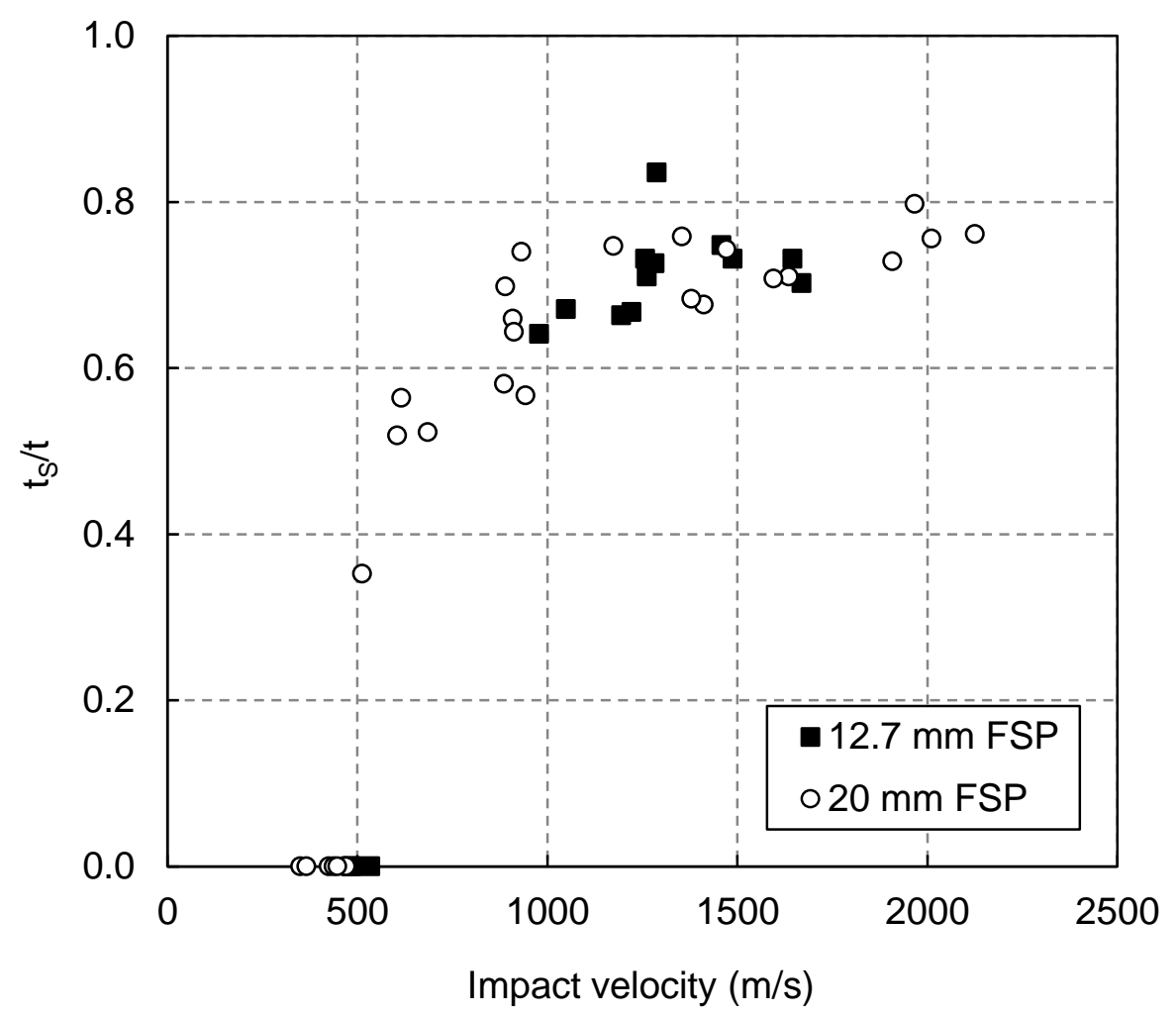

Figure 6: Ratio of panel thickness penetrated through shear plugging to total panel thickness in terms of impact velocity.

\section{Perforation Model}

As presented in the previous section, thick UHMW-PE composite panels were observed to resist penetration in two stages: initial penetration by shear plugging followed by a bulging stage where the panel behaves like a membrane failing in tension. In the following section, equations to define each of these stages are derived from consideration of energy and momentum laws. The assumptions used in these equations are based on the experimental observations and discussion presented previously. The equations are combined to determine the total energy absorbed by the target, and thus provide predictions of the ballistic limit.

\subsection{Shear Plugging}

The following assumptions are made for the analytical formulation of the shear plugging stage:

- Non-deforming projectile. The significantly higher hardness of the steel FSP compared to UHMW-PE composite target justifies the assumption of a non-deforming projectile for the initial penetration stage;

- Penetration by transverse shear. Transverse fibre shearing was observed to be the dominant failure mechanism in this stage of penetration (Figure 8);

- No forward momentum transfer to the plug, as plug material is considered to be ejected from the target front face;

- Energy absorbed due to fibre tension and compression is negligible.

- Energy associated with delamination, ply splitting and fibre-matrix debonding is ignored, as the matrix properties of UHMW-PE composite are very low;

- Shock induced heating is ignored, as the melting temperature and thermal conductivity of UHMW-PE composite is low [21]. 
The energy to perforate material around the perimeter of a blunt projectile, is equal to the work required to produce a shear plug, where the shear area is the circumference of the projectile multiplied by the thickness of the material in the shear plugging stage. This is given by

$$
E_{S}=\int_{0}^{t_{S}} \tau_{\max }\left(2 \pi r_{p}\right) t d t=\tau_{\max } \pi r_{p} t_{S}^{2}
$$

where $E_{S}$ is the energy absorbed in shear plugging, $\tau_{\max }$ is the effective through-thickness shear strength of the laminate, and $r_{p}$ is the projectile radius. Similar equations that describe the development of a shear plug have been derived elsewhere $[19,20,21]$.

For the through-thickness shear strength $\tau_{\max }$ of the laminate, currently no methods exist to characterise this at ballistic strain rates. Further, the high fibre volume fraction of around $80 \%$ means that this property is more related to the fibres, instead of being related to the matrix as with most fibrereinforced composites. Experiments characterising the quasi-static shear properties of single fibre filaments have been developed [22,23], however these are not representative of the throughthickness shear properties of the laminate, or known to be suitable for high strain rates. As such, a series of three Depth of Penetration (DoP) tests were performed on semi-infinite panels to allow an energy-based approach for determining an effective laminate through-thickness shear strength. The DoP tests were performed on $100 \mathrm{~mm}$ and $150 \mathrm{~mm}$ thick laminates, measuring 150x150 mm laterally, formed through the secondary pressing method described in section 2 . The panels were backed with $100 \mathrm{~mm}$ steel blocks in order to prevent deformation at the rear of the panel and impacted with $20 \mathrm{~mm}$ FSP at the centre. The thicknesses of the DoP targets were selected to be more than double the predicted DoP in order to minimize the effects of the steel backing. Fibre fracture morphology studies were performed on fibres throughout the entire penetration cavity and showed the same failure morphologies as those depicted in Figure 8(a) and Figure $8(\mathrm{~b})$ in the shear plugging stage of the ballistic limit targets. The penetration mechanisms of the two conditions are the same so the DoP test is used to predict the behaviour of the shear plugging stage of the ballistic limit targets.

Assuming penetration by pure transverse shearing, the impact kinetic energy of the projectile is equal to the work required to form a shear plug, where the thickness of the plug is equal to the measured DoP, therefore

$$
\frac{1}{2} m_{p} V_{i}^{2}=\tau_{\max } \pi r_{p} \mathrm{DoP}^{2}
$$

where $m_{p}$ is the projectile mass and $V_{i}$ is the impact velocity. Equation (2) is solved for the effective through-thickness shear strength using the DoP test data, and the results are presented in Table 3. The effective shear strength calculated in this manner is very similar for the two lower impact velocities, though is significantly lower for the highest impact velocity. This may be due to different target thickness used for the two lower velocities (100 mm thick) compared to the highest impact velocity case (150 mm thick). As a first approximation, the average effective shear strength of 560 $\mathrm{MPa}$ is used to estimate the ballistic limit velocity.

Table 2: Depth of penetration tests for estimating through-thickness shear strength

\begin{tabular}{cccc}
\hline Thickness $(\mathrm{mm})$ & Impact Velocity $(\mathrm{m} / \mathrm{s})$ & DoP $(\mathrm{mm})$ & $\tau_{\max }(\mathrm{MPa})$ \\
\hline 100.8 & 815.0 & 30.0 & 635 \\
100.6 & 1139.5 & 41.2 & 657 \\
150.8 & 1304.6 & 61.4 & 387 \\
\hline
\end{tabular}

\subsection{Bulging}

The assumptions made for the analytical formulation of the bulging stage are: 
- A deformed projectile. A deformed projectile reduces the stress concentration on the composite around the projectile and is particularly important to take into account for the late bulging stage. Recovered projectiles are shown in Figure 6 for a range of impact velocities. Minimal deformation is expected for velocities below $500 \mathrm{~m} / \mathrm{s}$, while at velocities up to 1410 $\mathrm{m} / \mathrm{s}$ a degree of mushrooming can be observed;

- Failure by fibre tension. Fibre tensile failure was found to be dominant under this stage of penetration (Figure 8);

- The panel under this stage is treated as a membrane. The large degree of delamination in this stage allows the individual plies to respond independently. The individual plies have negligible bending resistance;

- As with the shear plugging stage, energy associated with delamination and shock induced heating is ignored.
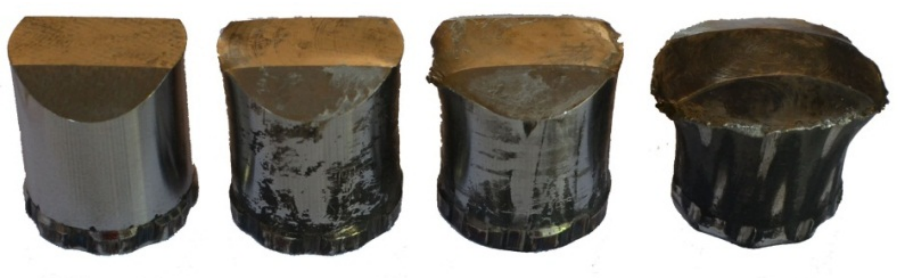

\section{$20 \mathrm{~mm}$}

Figure 7: $20 \mathrm{~mm}$ FSPs from partially penetrated ballistic limit tests. Impact velocity (left to right): $365 \mathrm{~m} / \mathrm{s}$, $615 \mathrm{~m} / \mathrm{s}, 911 \mathrm{~m} / \mathrm{s}, 1410 \mathrm{~m} / \mathrm{s}$.

According to conservation of momentum, the momentum of the system just before and after the initial breakout, shown in Figure 10, is equal, so that

$$
\begin{gathered}
m_{p} V_{B}=\left(m_{p}+m_{B}\right) V \\
V_{B}=V\left(1+\frac{m_{B}}{m_{p}}\right)=V\left(1+\beta^{2} \frac{\pi r_{p}^{2} t_{B} \rho}{m_{p}}\right)=V\left(1+\beta^{2} \frac{t_{B} \rho A_{p}}{m_{p}}\right),
\end{gathered}
$$

where $V_{B}$ is the projectile velocity just before breakout to bulging, $m_{B}$ is the mass of the target in the bulging stage initially involved in the momentum transfer, $V$ is the velocity of the combined projectile and bulging mass just after initial breakout, $A_{p}$ is the projectile presented area, and $\beta$ is a nondimensional multiplier for $r_{p}$ as shown in Figure 10. The $\beta$ parameter accounts for the fact that the initial momentum transfer to the target just after breakout occurs over a radius larger than the projectile radius, and has been used by other authors [27, 28]. 


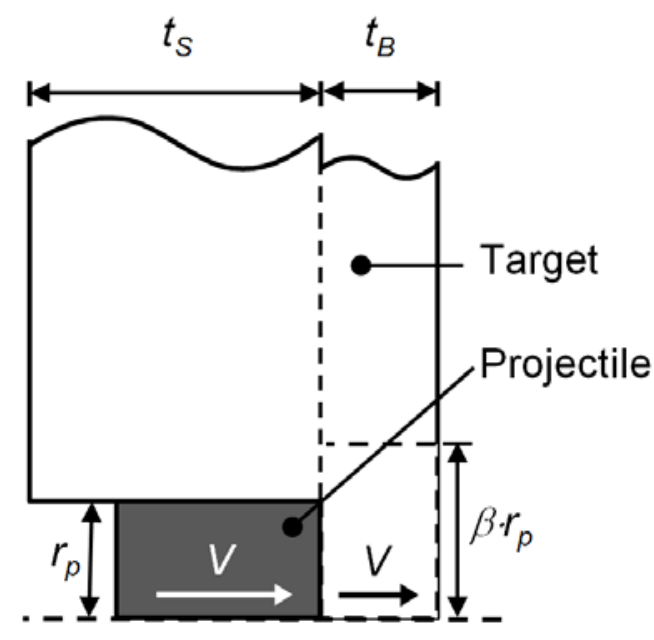

Figure 8: Momentum exchange at initiation of bulging.

Smith et al. [29] classical theory describes the wave propagation of a textile yarn impacted transversely. The relationship between the impact velocity $V$ (which is constant after impact because the filament mass is negligible), the speed of wave propagation $c$, and the strain that develops as the longitudinal wave propagates through the filament is given by

$$
V=c \sqrt{2 \varepsilon \sqrt{\varepsilon+\varepsilon^{2}}-\varepsilon^{2}} .
$$

This relationship has been shown to be applicable for UHMW-PE composite [5]. The speed of wave propagation $c$ according to Smith et al. [29] is

$$
c=\sqrt{\frac{1}{M} \frac{d T}{d \varepsilon}} .
$$

where $M$ is the mass per unit length of the unstrained material, $d T / d \varepsilon$ is the slope of the tension force-strain curve. UHMW-PE composite exhibits linear stress-strain behaviour with increasing strain rate in tension [14], therefore the derivative term reduces to the tension-strain ratio. For a cross-ply composite it is assumed that only the longitudinal fibres carry the tensile load. The tensile force is therefore adjusted to account for the cross-ply layup and fibre volume fraction

$$
\frac{d T}{d \varepsilon}=\frac{T}{\varepsilon}=\frac{\sigma_{f} v_{f} A}{2 \varepsilon}
$$

where $T$ is the tension force, $\sigma_{f}$ is the stress in the fibres, $v_{f}$ is the fibre volume fraction and $A$ is the area over which the load is applied.

Substituting (6) and (7) into (5), $\sigma_{f} / \varepsilon$ for $E_{f}$, the fibre elastic modulus, and $M$ for $\rho A$ (where $\rho$ is the fibre density) gives

$$
V=\sqrt{\frac{E_{f}}{\rho}} \sqrt{\frac{v_{f}}{2}} \sqrt{2 \varepsilon \sqrt{\varepsilon+\varepsilon^{2}}-\varepsilon^{2}}
$$

Substituting (8) into (4) yields

$$
V_{B}=\left(1+\beta^{2} \frac{t_{B o} \rho A_{p}}{m_{p}}\right) \sqrt{\frac{E_{f}}{\rho}} \sqrt{\frac{v_{f}}{2}} \sqrt{2 \varepsilon \sqrt{\varepsilon+\varepsilon^{2}}-\varepsilon^{2}} .
$$


If small strain is assumed and the squared strain terms are in turn removed, equation (9) reduces down to equations derived by Phoenix and Porwal [28] (without adjustment for the fibre volume fraction) to describe a fabric membrane impacted by a projectile. Phoenix and Porwal's model further incorporates strain concentration around the projectile which decays to unity for thicker targets or large projectile to bulge radius ratios. As the projectile deformation increases with increasing impact velocity for thicker targets (as shown in Figure 6) strain concentration diminishes [28]. Since this model applies to thick composites that are penetrated in two stages, strain concentration is ignored. Further, the small strain assumption is not applied. Substituting the strain $\varepsilon$ for the failure strain $\varepsilon_{\max }$, the energy absorbed in the bulging stage is given by

$$
E_{B}=\frac{1}{2} m_{p} V_{B}^{2}=\frac{1}{2} m_{p}\left(1+\beta^{2} \frac{t_{B} \rho A_{p}}{m_{p}}\right)^{2} \frac{E_{f}}{\rho} \frac{v_{f}}{2}\left(2 \varepsilon_{\max } \sqrt{\varepsilon_{\max }+\varepsilon_{\max }^{2}}-\varepsilon_{\max }^{2}\right) .
$$

\subsection{Ballistic Limit}

At the ballistic limit, the kinetic energy of the projectile is assumed equal to the energy absorbed during the two stages of penetration, so that

$$
E_{\text {total }}=\frac{1}{2} m_{p} \mathrm{~V}_{50}^{2}=E_{S}+E_{B}
$$

Substituting (1) and (10) into (11) and rearranging for $\mathrm{V}_{50}$ gives

$$
\mathrm{V}_{50}=\sqrt{\frac{2}{m_{p}} \tau_{\max } \pi r_{p} t_{s}^{2}+\left(1+\beta^{2} \frac{t_{B} \rho A_{p}}{m_{p}}\right)^{2} \frac{E_{f}}{\rho} \frac{v_{f}}{2}\left(2 \varepsilon_{\max } \sqrt{\varepsilon_{\max }+\varepsilon_{\max }^{2}}-\varepsilon_{\max }^{2}\right)} .
$$

The thickness in the shear plugging and bulging stages can be related to the total thickness using the term $k$ which defines the shear plugging thickness ratio, so that

$$
t_{S}=k t \quad \text { and } \quad t_{B}=(1-k) t .
$$

Substituting (13) into (12) and substituting $t$ for $A D_{t} / \rho$ gives the ballistic limit equation:

$$
V_{50}=\sqrt{\frac{2}{m_{p} \rho^{2}} \tau_{\max } \pi r_{p} k^{2} A D_{t}^{2}+\left(1+\beta^{2}(1-k) \frac{A D_{t} A_{p}}{m_{p}}\right)^{2} \frac{E_{f}}{\rho} \frac{v_{f}}{2}\left(2 \varepsilon_{\max } \sqrt{\varepsilon_{\max }+\varepsilon_{\max }^{2}}-\varepsilon_{\max }^{2}\right)} .
$$

For the parameter $k$, this is determined empirically. Figure 11 plots $t_{S} / t$ (or $k$ ) against the Cunniff non-dimensional areal density parameter for test cases impacted within $5 \%$ of the calculated $V_{50}$. The relationship is similar to the one shown in Figure 9, but the use of data close to the ballistic limit is more suitable for determining an empirical relationship for $k$. Further, the Cunniff parameter is used to define the transition between single stage perforation and two-stage perforation, that is, between thin and thick targets. 


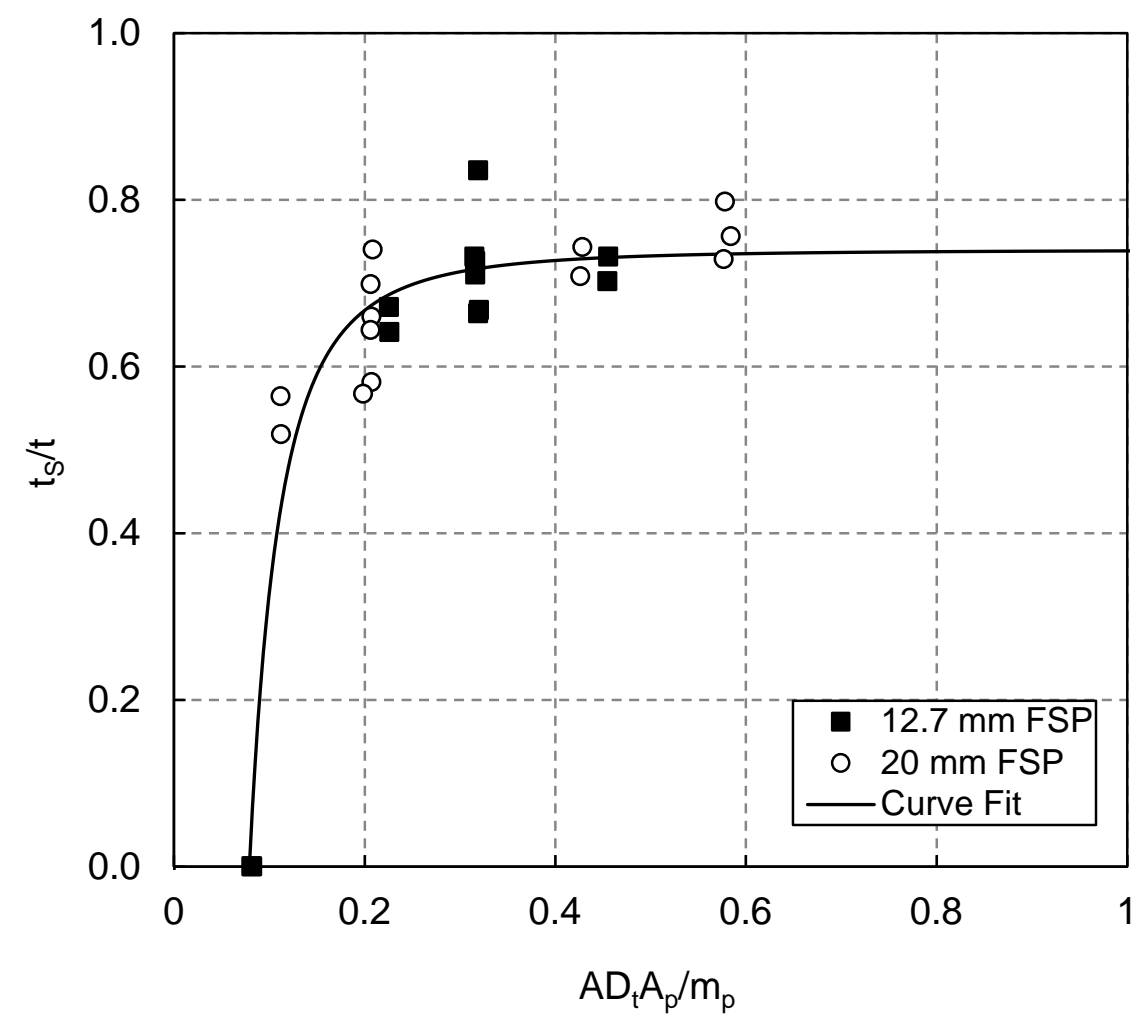

Figure 9: Shear plugging thickness ratio. Data points are within $5 \%$ of the calculated ballistic limit.

From Figure 11, a power law relationship is used, such that

$$
k=C_{1}\left(\frac{A D_{t} A_{p}}{m_{p}}\right)^{C_{2}}+C_{3} \quad \frac{A D_{t} A_{p}}{m_{p}} \geq C_{T}
$$

where the constants $C_{1}, C_{2}, C_{3}$ are curve fit parameters, and $C_{T}$ is the Cunniff parameter that defines the transition between thin and thick targets.

Equations (14) and (15) define the ballistic limit equation for a blunt projectile impacting a thick UHMW-PE composite target that undergoes two stages of penetration. The ballistic limit equation was applied to the experimental $V_{50}$ data to demonstrate the applicability of the equation for thick targets. The following parameters were used:

- $\quad E_{f}=131 \mathrm{GPa}$ and $\varepsilon_{\max }=0.02$, from high strain rate characterisation of Dyneema ${ }^{\circledR}$ SK76 fibre [14]. UHMW-PE is highly strain-rate sensitive, though UHMW-PE yarn has been found to be insensitive at strain rates above $10^{-1} \mathrm{~s}^{-1}$.

- Target fibre density $\rho=970 \mathrm{~kg} / \mathrm{m}^{3}$ and volume fraction $v_{f}=0.83$ [14]

- $\tau_{\max }=560 \mathrm{MPa}$ from the average of values in Table 3

- $\quad$ Radius multiplier $\beta=1.4$, which is within the range of 1.3-1.5 used in Phoenix and Porwal [28] and Walker [27] for a range of fabric-based armour materials. Note that the ballistic limit equation does not show any significant sensitivity to the value of $\beta$ within this range.

- $k$ parameters $C_{1}=-0.0013, C_{2}=-2.5, C_{3}=0.74$ and $C_{T}=0.08$, from the curve fit shown in Figure 11.

In addition, analytical membrane models from Phoenix and Porwal [28] and Walker [27] are used to provide predictions for thin targets, and to compare with the developed ballistic limit equation for thick targets. These models were developed for fabrics, but have not been demonstrated for application 
with thin UHMW-PE composite. For these models, the values of $E_{f}, \varepsilon_{\max }$ and $\beta$ defined above are used.

Figure 12 compares the model predictions with the $\mathrm{V}_{50}$ data for UHMW-PE composite against three different calibre FSPs, where additional experimental data has been taken from literature. From these results, the proposed perforation model provides very good agreement with experimental ballistic limits for thick targets. For target thicknesses close to the transition point (around $A D_{t} A_{p} / m_{p}=0.08$ ), the predictions of the perforation model deviate slightly from the experimental results. This is because the target response in this regime is still dominated by the membrane action in bulging, and strain concentration effects near the projectile edge are important to consider. These aspects are accounted for in the membrane models plotted, though these models provide very poor predictions of ballistic performance for thick targets. The results show that either membrane model plotted in the figure is suitable to predict the ballistic limit of thin targets, and the proposed two-stage perforation model is suitable for thick laminates.

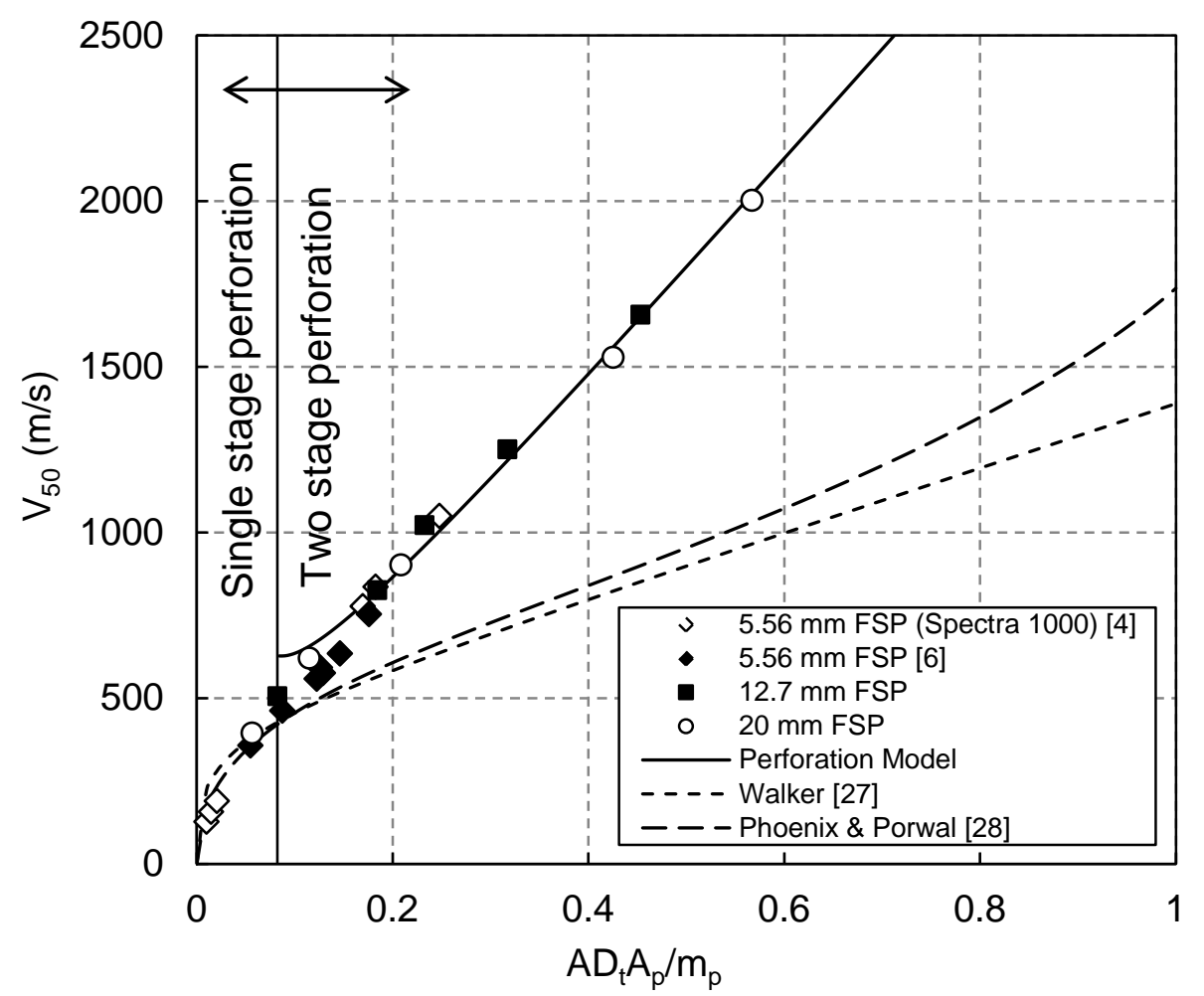

Figure 10: Ballistic limit experimental and analytical results.

\section{Conclusion}

An extensive experimental program was conducted to understand the ballistic performance of UHMW-PE composite panels. Ballistic limit testing was performed for panel thicknesses up to $100 \mathrm{~mm}$ using $12.7 \mathrm{~mm}$ and $20 \mathrm{~mm}$ calibre FSPs. The ballistic limit tests showed that penetration of thick UHMW-PE composite occurs in two stages. The first stage was shear plugging, where penetration occurs in fibre shearing with no deflection of the target, and the second stage was bulging, where a sub-laminate breaks away from the target and undergoes large deflection and penetration in fibre tension, commonly observed in fabrics. Characterisation of the fibre fracture morphology throughout the penetration cavity showed fibre failure in transverse shear in the shear plugging stage, and tensile fibre failure in the bulging stage. Delamination occurred in both stages of penetration, and was also important in forming a transition plane between the sections of the target undergoing either shear plugging or bulging. Transition between the two stages of penetration was found to be dependent on 
the impact velocity and target thickness, and the thickness of each stage was characterised for increasing impact velocity. Thin laminates were found to show penetration with only the bulging stage, with shear failure on the impact surface, and no transition plane.

A two-stage perforation model based on conservation of energy and momentum was developed that describes the shear plugging and bulging stages for thick UHMW-PE composite. The shear plugging stage was described using the work done in shear by the plug, and used a through-thickness shear strength characterised from DoP tests. The bulging stage was described using the kinetic energy at the initiation of bulging, with the projectile velocity found from considering momentum transfer. The two-stage perforation model provided very good agreement with experimental ballistic limit results for thick targets. For thin targets, analytical models for membranes were applied and demonstrated as suitable for predicting the ballistic limit of targets undergoing only bulging. These models allow for the successful prediction of ballistic limit for targets at any thickness, are based on experimental observations of UHMW-PE and experimentally characterised parameters, and provide key insight into the mechanisms governing penetration.

\section{Acknowledgement}

The authors would like to acknowledge Mr Frank Griffo and Mr Steve Pattie of DSTO, and the Joint Proof and Experiment Unit of the Australian Department of Defence for assisting with ballistic testing. Mr Griffo and the RMIT Microscopy and Microanalysis Facility are also gratefully acknowledged for SEM facilities and support. The authors would also like to acknowledge the support of all other DSTO staff that assisted in material processing.

\section{Reference}

[1] P. M. Cunniff, "Dimensionless parameters for optimization of textile based body armor systems," in 18th International Symposium and Ballistics, 1999, pp. 1303-1310.

[2] C. W. Ong, C. W. Boey, R. S. Hixson, and J. O. Sinibaldi, "Advanced layered personnel armor," International Journal of Impact Engineering, vol. 38, no. 5, pp. 369-383, 2011.

[3] E. Gellert, S. Cimpoeru, and R. Woodward, "A study of the effect of target thickness on the ballistic perforation of glass-fibre-reinforced plastic composites," International Journal of Impact Engineering, vol. 24, pp. 445-456, 2000.

[4] B. L. Lee, J. W. Song, and J. E. Ward, "Failure of Spectra Polyethylene Fiber-Reinforced Composites under Ballistic Impact Loading," Journal of Composite Materials, vol. 28, no. 13, pp. 1202-1226, 1994.

[5] S. Chocron, N. King, R. Bigger, J. D. Walker, U. Heisserer, H. Van der Werff, and A. Nicholls, "Impacts and waves in Dyneema HB80 Strips and Laminates," Journal of Applied Mechanics, vol. 80, no. 3, pp. 1075-1078, Apr. 2013.

[6] U. Heisserer and H. Van der Werff, "The relation between Dyneema ${ }^{\circledR}$ fiber properties and ballistic protection performance of its fiber composites," in 15th International Conference on Deformation, Yield and Fracture of Polymers, 2012, vol. 3, no. 3, pp. 242-246.

[7] U. Heisserer, H. Van der Werff, and J. Hendrix, "Ballistic Depth of Penetration Studies in Dyneema Composites," in 27th International Symposium on Ballistics, 2013.

[8] M. Iremonger, "Polyethylene composites for protection against high velocity small arms bullets," in 18th International Symposium on Ballistics, 1999, pp. 946-953.

[9] E. S. Greenhalgh, V. M. Bloodworth, L. Iannucci, and D. Pope, "Fractographic observations on Dyneema ${ }^{\circledR}$ composites under ballistic impact," Composites Part A: Applied Science and Manufacturing, vol. 44, no. 2013, pp. 51-62, 2013.

[10] S. S. Morye, P. J. Hine, R. A. Duckett, D. J. Carr, and I. M. Ward, "Modelling of the energy absorption by polymer composites upon ballistic impact," Composites Science and Technology, vol. 60, no. 14, pp. 2631-2642, 2000. 
[11] S. Chocron, T. Kirchdoerfer, N. King, and C. J. Freitas, "Modeling of Fabric Impact With High Speed Imaging and Nickel-Chromium Wires Validation," Journal of Applied Mechanics, vol. 78, no. $5,2011$.

[12] H. Wen, "Penetration and perforation of thick FRP laminates," Composites Science and Technology, vol. 61, pp. 1163-1172, 2001.

[13] I. S. Chocron, J. Rodriguez, and V. Sanchez-Galvez, "A simple analytical model for ballistic impact in composites," Journal de Physique IV, vol. 7, no. C3, pp. 821-826, 1997.

[14] B. P. Russell, K. Karthikeyan, V. S. Deshpande, and N. A. Fleck, "The high strain rate response of Ultra High Molecular-weight Polyethylene: From fibre to laminate," International Journal of Impact Engineering, vol. 60, pp. 1-9, 2013.

[15] V. Tan and K. Khoo, "Perforation of flexible laminates by projectiles of different geometry," International Journal of Impact Engineering, vol. 31, no. 7, pp. 793-810, 2005.

[16] S. Chocron, E. Figueroa, N. King, T. Kirchdoerfer, A. Nicholls, E. Sagebiel, C. Weiss, and C. Freitas, "Modeling and validation of full fabric targets under ballistic impact," Composites Science and Technology, vol. 70, no. 13, pp. 2012-2022, 2010.

[17] S. L. Phoenix and J. Skelton, "Transverse Compressive Moduli and Yield Behavior of Some Orthotropic, High-Modulus Filaments," Textile Research Journal, vol. 44, no. 12, pp. 934-940, 1974.

[18] M. Cheng, W. Chen, and T. Weerasooriya, "Experimental investigation of the transverse mechanical properties of a single Kevlar® KM2 fiber," International Journal of Solids and Structures, vol. 41, no. 22-23, pp. 6215-6232, 2004.

[19] L. Berger, H. Kausch, and C. Plummer, "Structure and deformation mechanisms in UHMWPEfibres," Polymer, vol. 44, no. 19, pp. 5877-5884, 2003.

[20] C. Koh, V. Shim, V. Tan, and B. Tan, "Response of a high-strength flexible laminate to dynamic tension," International Journal of Impact Engineering, vol. 35, no. 6, pp. 559-568, 2008.

[21] D. C. Prevorsek, Y. D. Kwon, and H. B. Chin, "Analysis of the temperature rise in the projectile and extended chain polyethylene fiber composite armor during ballistic impact and penetration," Polymer Engineering \& Science, vol. 34, no. 2, pp. 141-152, 1994.

[22] R. L. Woodward and S. J. Cimpoeru, "A study of the perforation of aluminium laminate targets," International Journal of Impact Engineering, vol. 21, no. 3, pp. 117-131, 1998.

[23] R. L. Woodward, "The penetration of metal targets which fail by adiabatic shear plugging," International Journal of Mechanical Science, vol. 20, pp. 599-607, 1978.

[24] T. Atkins, "Perforation of metal plates due to through-thickness shearing and cracking. Optimum toughness/strength ratios, deformation transitions and scaling," International Journal of Impact Engineering, vol. 48, pp. 4-14, 2012.

[25] M. Hudspeth, X. Nie, and W. Chen, "Dynamic failure of Dyneema SK76 single fibers under biaxial shear/tension," Polymer, vol. 53, no. 24, pp. 5568-5574, 2012.

[26] S. Deteresa, S. Allen, R. Farris, and R. Porter, "Compressive and torsional behaviour of Kevlar 49 fibre," Journal of Materials Science, vol. 19, pp. 57-72, 1984.

[27] J. D. Walker, "Constitutive model for fabrics with explicit static solution and ballistic limit," in 18th International Symposium on Ballistics, 1999, vol. 2, pp. 1231-1238.

[28] S. L. Phoenix and P. K. Porwal, "A new membrane model for the ballistic impact response and V50 performance of multi-ply fibrous systems," International Journal of Solids Structures, vol. 40, pp. 6723-6765, 2003.

[29] J. C. Smith, F. L. McCrackin, and H. F. Schiefer, "Stress-Strain Relationships in Yarns Subjected to Rapid Impact Loading: Part V: Wave Propagation in Long Textile Yarns Impacted Transversely," Textile Research Journal, vol. 28, no. 4, pp. 288-302, 1958. 